\title{
Factors Affecting Energy Metabolism and Prognosis in Patients with Amyotrophic Lateral Sclerosis
}

\author{
Mika Kurihara $^{a}$ Shigeki Bamba ${ }^{a}$ Shoko Yasuhara ${ }^{a}$ Akihiko ttoh $^{b}$ \\ Taishi Nagaoc Naoko Nakanishi ${ }^{d}$ Ryutaro Nakamura ${ }^{d}$ Nobuhiro Ogawa $^{d}$ \\ Akihiro Kitamura $^{d}$ Isamu Yamakawa $^{d}$ Hyou Kim $^{d}$ Mitsuru Sanadad \\ Makoto Urushitani $^{\text {d }}$ Masaya Sasaki $^{\mathrm{a}}$
}

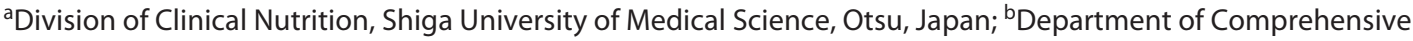
Internal Medicine, Shiga University of Medical Science, Otsu, Japan; ${ }^{\circ}$ Medical Education Center, Shimane University Hospital, Izumo, Japan; dDepartment of Neurology, Shiga University of Medical Science, Otsu, Japan

\section{Keywords}

Sarcopenia · Body composition · Indirect calorimetry

\begin{abstract}
Background/Aims: Nutritional status is a factor affecting prognosis in patients with amyotrophic lateral sclerosis (ALS). Here, we aimed to clarify the factors associated with hypermetabolism and the prognosticators of ALS. Methods: Forty-two inpatients (22 men, 20 women) diagnosed with ALS according to the revised El-Escorial criteria were investigated. The following data were retrospectively analyzed: anthropometric measurements, blood biochemistry, disease severity, basal energy expenditure (BEE), resting energy expenditure (REE) measured by indirect calorimetry, spirometry, and bioelectrical impedance analysis. Single and multiple regression analysis was performed to examine factors affecting REE and metabolic changes (defined as the ratio of REE to fat-free mass [FFM]). The Kaplan-Meier method was used to examine factors associated with the occurrence of cumulative events (death or tracheostomy). Results: Among the 42 inpatients, REE was significantly higher than BEE, indicating hypermetabolism in ALS. Multiple regression analysis
\end{abstract}

karger@karger.com www.karger.com/anm

Karger ${ }^{\prime \prime} \div$
(C) 2021 The Author(s)

Published by S. Karger AG, Basel

This article is licensed under the Creative Commons Attribution 4.0 International License (CC BY) (http://www.karger.com/Services/ OpenAccessLicense). Usage, derivative works and distribution are permitted provided that proper credit is given to the author and the original publisher. revealed that REE/FFM is strongly associated with the skeletal muscle index $(-3.746$ to $-1.532, p<0.0001)$ and percent forced vital capacity (\%FVC) $(-0.172$ to $-0.021, p=0.013)$. Moreover, both the skeletal muscle index and \%FVC were significant prognosticators associated with the occurrence of cumulative events. Conclusions: Energy metabolism was elevated in ALS, and respiratory status and muscle mass were associated with the hypermetabolism and poor prognosis. Adequate nutritional support may improve outcomes in ALS by preventing deterioration of respiratory status and reduction in muscle mass.

(c) 2021 The Author(s).

Published by S. Karger AG, Basel

\section{Introduction}

Amyotrophic lateral sclerosis (ALS) is a fatal paralytic disorder with a longevity of 2-4 years unless mechanical ventilation is introduced $[1,2]$. Various clinical features of ALS affect the prognosis of the disease. Previously reported prognostic factors of ALS include bulbar palsy [3, 4], respiratory muscle disorder/injury [5], older age at onset $[3,6,7]$, malnutrition at diagnosis or during the dis- 
ease course $[8,9]$, low body mass index (BMI) [10], Revised Amyotrophic Lateral Sclerosis Functional Rating Scale (ALSFRS-R) score $[11,12]$, and percent forced vital capacity (\%FVC) [12-14]. Above all, recent evidence shows the presence of elevated energy metabolism [15$19]$ in ALS, which underlies the body weight reduction seen in the disease, as well as insufficient energy intake [2]. Notably, early nutritional intervention with a high calorie diet significantly improves prognosis $[1,2]$. However, how hypermetabolism exacerbates the clinical course of ALS is still unclear.

On the other hand, the respiratory muscle weakness that occurs with ALS progression results in decreased ventilation volume, labored respiration, and increased respiratory rate, and this decline in respiratory status has been shown to be associated with increased energy metabolism [20, 21]. Moreover, upon further deterioration of respiratory function, the burden on the respiratory muscles can be reduced by tracheostomy-positive pressure ventilation, which decreases energy metabolism [22]. Therefore, it is necessary to elucidate the role of energy metabolism in respiratory function during the clinical course of ALS.

Evaluating energy requirement in ALS is crucial but also difficult due to confounding factors such as obesity, sex, and ethnicity. Based on the insufficient energy expenditure calculated using the Harris-Benedict equation [23], Shimizu and colleagues [24] proposed a standard formulation to estimate the total energy expenditure (TEE) of Japanese ALS patients, which uses ALSFRS-R, age, body weight, and height. Another convenient method for estimating an individual's energy requirement is to use the resting energy expenditure (REE) determined by indirect calorimetry. To assess energy metabolism, REE alone cannot be used as a strict marker of metabolic changes because it has been shown to correlate strongly with body composition, especially fat-free mass (FFM). Therefore, FFM-adjusted REE (REE divided by FFM) [25] has become an accepted indicator for assessing metabolic changes. In this study, we retrospectively analyzed indirect calorimetry, body composition, and spirometry in 42 hospitalized ALS patients to ascertain the factors involved in energy metabolism and prognosis.

\section{Materials and Methods}

\section{Patients and Ethical Considerations}

We retrospectively collected cases of patients with ALS according to the revised El-Escorial criteria who had been admitted to Shiga University of Medical Science Hospital from March 2018 to
May 2020 and who did not use a respirator and had undergone indirect calorimetry, body composition analysis, and spirometry. A total of 42 patients (22 men and 20 women) were enrolled in this study. Among them, 36 patients were admitted for diagnostic reasons and 6 patients were admitted for percutaneous endoscopic gastrostomy placement, which was performed due to dysphagia. All clinical parameters were collected before percutaneous endoscopic gastrostomy placement. None of the patients had infectious diseases or diseases other than ALS that affect energy metabolism.

\section{Clinical Parameters}

The following anthropometric measurements were obtained on admission: height $(\mathrm{cm})$, body weight (BW; $\mathrm{kg})$, and BMI $(\mathrm{kg} /$ $\mathrm{m}^{2}$ ). Bioelectrical impedance analysis was performed using a body composition analyzer $\left(\mathrm{S} 10^{\circledR}\right.$, InBody) to determine FFM (kg), body fat $(\mathrm{kg})$, and skeletal muscle index $\left(\mathrm{SMI} ; \mathrm{kg} / \mathrm{m}^{2}\right)$. The cutoff values of SMI for identifying low muscle mass were $7.0 \mathrm{~kg} / \mathrm{m}^{2}$ for men and $5.7 \mathrm{~kg} / \mathrm{m}^{2}$ for women, as proposed by the Japan Society of Hepatology [26]. The following biochemical test results were extracted 5 days before and 5 days after indirect calorimetry: total protein $(\mathrm{g} / \mathrm{dL})$, albumin $(\mathrm{g} / \mathrm{dL})$, total lymphocyte count $(/ \mu \mathrm{L})$, and C-reactive protein $(\mathrm{mg} / \mathrm{dL})$.

\section{Neurological Function Assessment}

The ALSFRS-R [27] was used to assess neurological function. The following 12 measures were rated on a 5-point scale from 0 to 4, with higher scores indicating more retained function: speech, salivation, swallowing, handwriting, cutting food and handling utensils, dressing and hygiene, turning in bed and adjusting bed clothes, walking, climbing stairs, dyspnea, orthopnea, and respiratory insufficiency.

\section{Respiratory Function Assessment}

Percent forced expiratory volume in $1 \mathrm{~s}$, tidal volume, and $\% \mathrm{FVC}$ were measured by spirometry. The cutoff for $\% \mathrm{FVC}$ was set at $80 \%$.

\section{Energy Metabolism}

Basal energy expenditure (BEE) was estimated using the Harris-Benedict equation [23]. REE, carbohydrate oxidation, fat oxidation, and respiratory quotient were measured by indirect calorimetry (Aeromonitor ${ }^{\circledR}$ AE310S, Minato Medical Science Co., Ltd.). REE was calculated using the Weir equation without the use of urinary nitrogen [28]. Respiratory quotient was calculated as carbon dioxide production divided by oxygen uptake $\left(\mathrm{VCO}_{2} /\right.$ $\mathrm{VO}_{2}$ ). Indirect calorimetry was performed in the morning after the patient had fasted overnight and rested in the supine position on a bed for $30 \mathrm{~min}$. The measurements took up to $10 \mathrm{~min}$ [29$32]$. Hypermetabolic rate $(\triangle \mathrm{REE}, \%)$ was obtained by dividing measured REE by BEE, and metabolic changes due to the disease were assessed using the ratio of measured REE to FFM (REE/ FFM). In this study, total energy expenditure (TEE) was estimated as the value obtained by multiplying REE by an activity factor $(\mathrm{REE} \times \mathrm{AF}) . \mathrm{AF}$ of 1.2 and 1.3 was used for bed rest and ambulatory status, respectively [33]. REE $\times$ AF was compared with the value obtained using the Shimizu equation [24] and the value obtained by multiplying BEE by an activity factor $(\mathrm{BEE} \times \mathrm{AF})$. The Shimizu equation is a prediction formula based on TEE values measured using the doubly labeled water method in 26 Japanese 
Table 1. Background characteristics of the inpatients with ALS in this study

\begin{tabular}{|c|c|c|c|c|}
\hline Characteristics & All $(n=42)$ & Male $(n=22)$ & Female $(n=20)$ & $p$ value \\
\hline Age, years & $70(61$ to 74$)$ & $68(59$ to 74$)$ & $73(63$ to 75$)$ & $0.230^{\dagger}$ \\
\hline $\mathrm{BMI}$ & $20.2(18.8$ to 22.1$)$ & $21.4(18.9$ to 22.2$)$ & $19.6(18.2$ to 22.1$)$ & $0.420^{\dagger}$ \\
\hline Height, cm & $160(154$ to 169$)$ & $168(162$ to 171$)$ & $153(151$ to 156$)$ & $<0.0001^{\dagger}$ \\
\hline Body weight, kg & $54(48$ to 61$)$ & $58(54$ to 64$)$ & $48(44$ to 52$)$ & $0.0003^{\dagger}$ \\
\hline Disease duration after onset, days & $424(267$ to 959$)$ & $380(243$ to 1,169$)$ & $466(303$ to 865$)$ & $0.772^{\dagger}$ \\
\hline Disease duration after diagnosis, days & $58(24$ to 269$)$ & $43(19$ to 201$)$ & $59(30$ to 299$)$ & $0.198^{\dagger}$ \\
\hline Family history (yes/no) & $3 / 39$ & $2 / 10$ & $1 / 19$ & $0.603^{\ddagger}$ \\
\hline ALSFRS-R & $38(35$ to 43$)$ & $36(32$ to 43$)$ & $39(35$ to 43$)$ & $0.397^{\dagger}$ \\
\hline Lymphocyte count, $/ \mathrm{mm}^{3}$ & $1,382(1,096$ to 1,819$)$ & $1,485(1,056$ to 1,772$)$ & $1,253(1,132$ to 1,973$)$ & $0.968^{\dagger}$ \\
\hline Albumin, $\mathrm{g} / \mathrm{dL}$ & $3.8(3.7$ to 4.2$)$ & $4.0(3.7$ to 4.4$)$ & $3.8(3.6$ to 4.2$)$ & $0.293^{\dagger}$ \\
\hline FFM, kg & $33.8(30.0$ to 40.6$)$ & $39.8(35.9$ to 44.2$)$ & $30.0(24.6$ to 33.5$)$ & $<0.0001^{\dagger}$ \\
\hline$\%$ Body fat, $\mathrm{kg}$ & 15.7 (12.9 to 20.6$)$ & $15.5(12.8$ to 19.7$)$ & $15.8(13.7$ to 20.7$)$ & $0.407^{\dagger}$ \\
\hline REE/FFM & $36.6(34.4$ to 41.2$)$ & $37.0(34.8$ to 39.7$)$ & $34.9(34.1$ to 43.2$)$ & $0.855^{\dagger}$ \\
\hline$\triangle \mathrm{REE}: \mathrm{REE} / \mathrm{BEE}$ & $1.07(0.99$ to 1.16$)$ & $1.15(1.08$ to 1.26$)$ & $0.99(0.97$ to 1.04$)$ & $<0.0001^{\dagger}$ \\
\hline $\mathrm{BEE} \times \mathrm{AF}$ & $1,483(1,372$ to 1,623$)$ & $1,567(1,468$ to 1,769$)$ & $1,376(1,333$ to 1,538$)$ & $0.0023^{\dagger}$ \\
\hline $\mathrm{REE} \times \mathrm{AF}$ & $1,627(1,378$ to 1,906$)$ & $1,895(1,721$ to 2,065$)$ & $1,394(1,347$ to 1,555$)$ & $<0.0001^{\dagger}$ \\
\hline Shimizu equation & $1,660(1,531$ to 1,923$)$ & $1,833(1,579$ to 2,091$)$ & $1,611(1,431$ to 1,819$)$ & $0.031^{\dagger}$ \\
\hline$\%$ FEV 1.0 & $80.5(72.6$ to 90.9$)$ & $80.6(70.9$ to 89.8$)$ & $82.2(75.5$ to 91.9$)$ & $0.610^{\dagger}$ \\
\hline Tidal volume, L & $0.66(0.52$ to 0.90$)$ & $0.86(0.69$ to 1.00$)$ & $0.58(0.49$ to 0.64$)$ & $0.0005^{\dagger}$ \\
\hline$\% \mathrm{FVC}$ & $86.1(65.0$ to 97.8$)$ & $87.7(62.9$ to 99.5$)$ & $86.1(64.9$ to 93.3$)$ & $0.793^{\dagger}$ \\
\hline Events* (yes/no) & $16 / 26$ & $9 / 13$ & $7 / 13$ & $0.758^{\ddagger}$ \\
\hline Observation period, days & $319(137$ to 440$)$ & 270 (97 to 362$)$ & $394(145$ to 560$)$ & $0.071^{\dagger}$ \\
\hline
\end{tabular}

Values are shown as the median (IQR). Bold text indicates statistically significant results. ALS, amyotrophic lateral sclerosis; IQR, interquartile range; ALSFRS-R, Revised Amyotrophic Lateral Sclerosis Functional Rating Scale; REE, resting energy expenditure; FFM, fat-free mass; BEE, basal energy expenditure; AF, activity factor; \%FEV 1.0, percent forced expiratory volume in $1 \mathrm{~s}$; \%FVC, percent forced vital capacity; BMI, body mass index; RQ, respiratory quotient. * Events were defined as death or tracheostomy. ${ }^{\dagger}$ Mann-Whitney U test. ${ }^{\ddagger} \chi^{2}$ test.

ALS patients and is expressed as follows: TEE (kcal/day) $=1.67 \times$ BEE $+11.8 \times$ ALSFRS-R -680 . A predictive formula for REE was derived using the data from our cohort, and REE $\times$ AF was also compared with the values obtained by multiplying predicted REE by an activity factor.

\section{Statistical Analysis}

All statistical analyses were performed using Prism, version 8.01 (GraphPad, San Diego, CA, USA), and JMP software, version 14.0 (SAS Institute, Cary, NC, USA). The $\chi^{2}$ test and MannWhitney $U$ test were used as appropriate. The Wilcoxon signed rank test and the Bland-Altman test were used to compare matched pairs. Single and multiple regression analyses were performed to determine factors affecting REE and metabolic changes. Wilcoxon analysis was performed to estimate the risk of events (death or tracheostomy). The cumulative event-free survival rate was calculated using the Kaplan-Meier method. Analysis was stratified by \%FVC, SMI, BMI, and ALSFRS-R. For stratification, median values were used for BMI and ALSFRS-R and the abovementioned cutoff values were used for \%FVC and SMI. The Wilcoxon test was used to determine statistical differences between groups. $p$ values were 2 -sided, with statistical significance set at $p<0.05$.

\section{Results}

\section{Patients}

A total of 42 patients were included in this study (22 men and 20 women). Their clinical backgrounds are shown in Table 1. Height, BW, and SMI were significantly higher in men than in women, and thus energy metabolism indexes such as BEE and REE were also higher in men (Table 1). Also, in this cohort of patients, $\triangle \mathrm{REE}$ was significantly higher in men than women. 


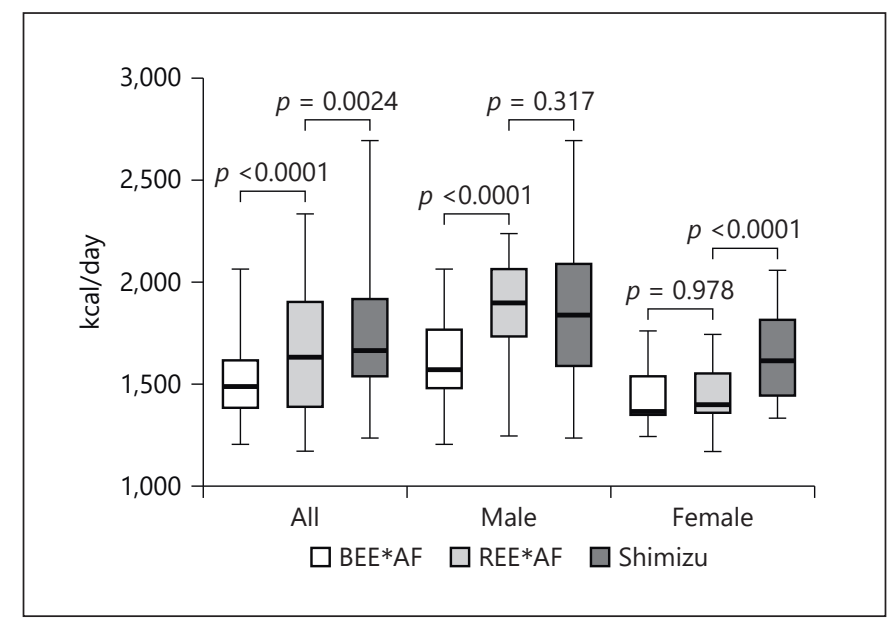

Fig. 1. Comparison of $\mathrm{BEE} \times \mathrm{AF}, \mathrm{REE} \times \mathrm{AF}$, and values obtained from the Shimizu equation. BEE, basal energy expenditure; REE, resting energy expenditure; $\mathrm{AF}$, activity factor.

\section{Energy Requirements}

REE was significantly higher than BEE in all patients $(p<0.0001)$ and in men $(p<0.0001)$ but not in women ( $p=0.956)$. Results of comparison of TEE were similar because the same active factor was used. The values obtained using the Shimizu equation were significantly higher than REE $\times$ AF in all patients $(p=$ $0.024)$ and in women $(p<0.0001)$ but not in men $(p=$ 0.317 , Fig. 1).

The Bland-Altman plot showed that $\mathrm{BEE} \times \mathrm{AF}$ tended to become lower than REE $\times$ AF with increased energy expenditure: the difference between $\mathrm{BEE} \times \mathrm{AF}$ and REE $\times$ AF was significant $(p<0.0001$, Fig. 2a). The differences between the values obtained using the Shimizu equation and $\mathrm{REE} \times \mathrm{AF}$ were also significant, but values obtained using the Shimizu equation were closer than $\mathrm{BEE} \times \mathrm{AF}$ to $\operatorname{REE} \times \operatorname{AF}(p=0.036$, Fig. $2 b)$.

\section{Factors Affecting REE or REE/FFM}

Single regression analysis was performed to find factors affecting REE measured by indirect calorimetry. Male sex, height, BW, BMI, BEE, FFM, SMI, and tidal volume were significantly associated with REE. SMI and $\%$ FVC were significant factors affecting REE/FFM (Table 2).

\section{Development of a Predictive Formula for REE}

To develop a predictive formula for REE, the parameters BEE, SMI, and tidal volume were tested in a stepwise manner. BEE and tidal volume were found to be signifi-

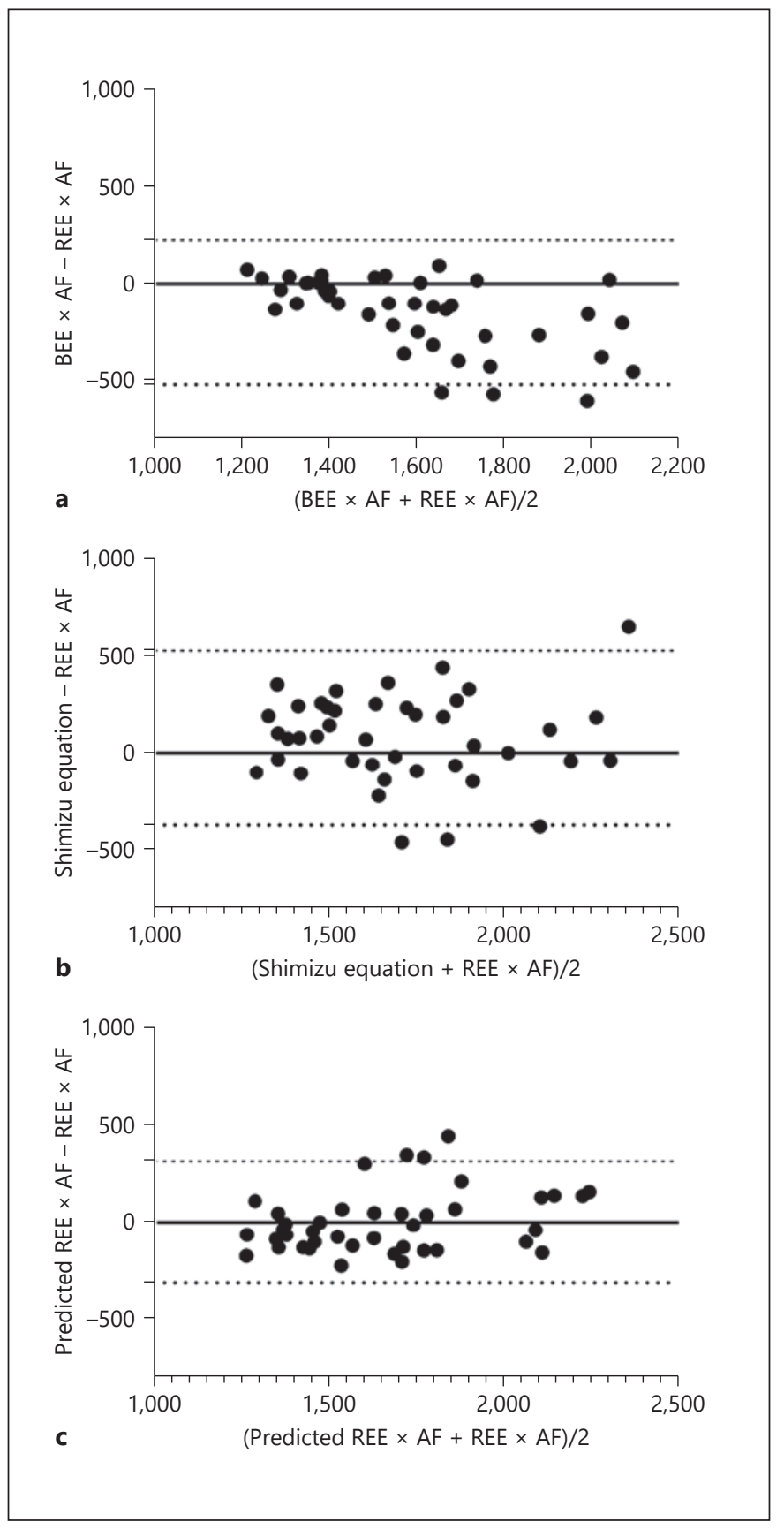

Fig. 2. Bland-Altman plot. REE $\times$ AF was compared with values given by $\mathrm{BEE} \times \mathrm{AF}(\mathbf{a})$, the Shimizu equation (b), and (c) the predictive equation derived in this study. BEE, basal energy expenditure; REE, resting energy expenditure; AF, activity factor.

cant factors and the following formula was derived for predicting REE in ALS patients not using a respirator: $\operatorname{REE}(\mathrm{kcal} /$ day $)=1.000251 \times \mathrm{BEE}(\mathrm{kcal} /$ day $)+313.3507$ $\times$ tidal volume $(\mathrm{L})-112.0360$. The Bland-Altman plot showed that, compared with BEE $\times$ AF and the values ob- 
Table 2. Regression analysis of factors affecting REE and REE/FFM

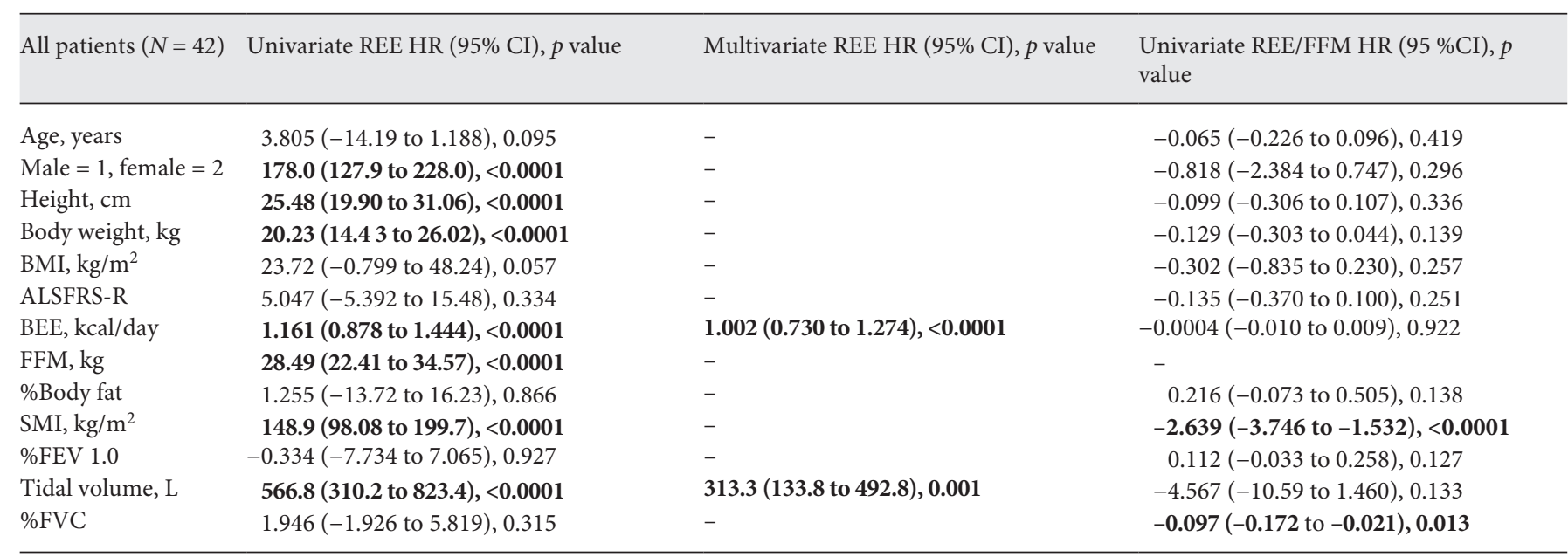

Bold text indicates statistically significant results. REE, resting energy expenditure; FFM, fat-free mass; HR, hazard ratio; CI, confidence interval; BMI, body mass index; ALSFRS-R, Revised Amyotrophic Lateral Sclerosis Functional Rating Scale; BEE, basal energy expenditure; SMI, skeletal muscle index; $\% \mathrm{FEV} 1.0$, percent forced expiratory volume in $1 \mathrm{~s} ; \% \mathrm{FVC}$, percent forced vital capacity.

tained using the Shimizu equation, predicted $\mathrm{REE} \times \mathrm{AF}$ was closer to measured REE $\times$ AF. There were no significant differences between predicted REE $\times \mathrm{AF}$ and measured $\operatorname{REE} \times \operatorname{AF}(p=0.985$, Fig. $2 c)$.

\section{Event-Associated Factors}

Factors associated with the event of death or tracheostomy were low \%FVC and low SMI (Fig. 3a, b). Although not statistically significant, low BMI or low ALSFRS-R tended to be associated with the event of death or tracheostomy (Fig. 3c, d).

\section{Discussion}

In this study, we ascertained that REE was significantly higher than BEE, indicating hypermetabolism in ALS. Hypermetabolism in ALS was negatively and significantly correlated with \%FVC and SMI, both of which are associated with poor prognosis of ALS.

Malnutrition is associated with poor prognosis in ALS, and nutritional support via a high calorie diet has improved prognosis [34], especially in rapidly progressive patients [35]. Therefore, the accurate calculation of energy requirement is essential for nutritional management. Although using indirect calorimetry to measure energy expenditure in individual patients is useful, it is not always available in all facilities, so a predictive formula such as the Harris-Benedict equation is commonly used. However, this study has shown that the values obtained by BEE (calculated using the Harris-Benedict equation) adjusted by AF were significantly lower than the values obtained by the REE adjusted by AF. Importantly, this trend was more prominent in men than in women. Hypermetabolism has been reported to be a factor affecting nutritional status in ALS [24, 36, 37]. In our cohort, median $\triangle \mathrm{REE}$ was 1.07 , indicating a $7 \%$ increase in metabolism. This increase was lower than the increases reported in Europe and North America [36, 38], probably due to the tendency toward overestimation with the Harris-Benedict equation in the Japanese population, especially in women [39]. Nevertheless, REE was still significantly higher than BEE, clearly indicating marked hypermetabolism in ALS.

Compared with the Shimizu equation, which is derived from the Harris-Benedict equation and ALSFRS-R score, $\mathrm{REE} \times \mathrm{AF}$ showed lower values, and this trend was more evident in women than in men. On the other hand, Bland-Altman plots showed that $\mathrm{BEE} \times \mathrm{AF}$ values became lower than measured REE $\times$ AF with increasing energy requirement. We performed multiple regression analysis to derive a formula for predicting REE and surprisingly found that tidal volume, but not ALSFRS-R, is a significant factor to be included in the calculation formula. The validity of the formula developed in this study needs to be examined in the future.

Factors related to body composition, such as sex, height, BW, SMI, and tidal volume, were found to be 

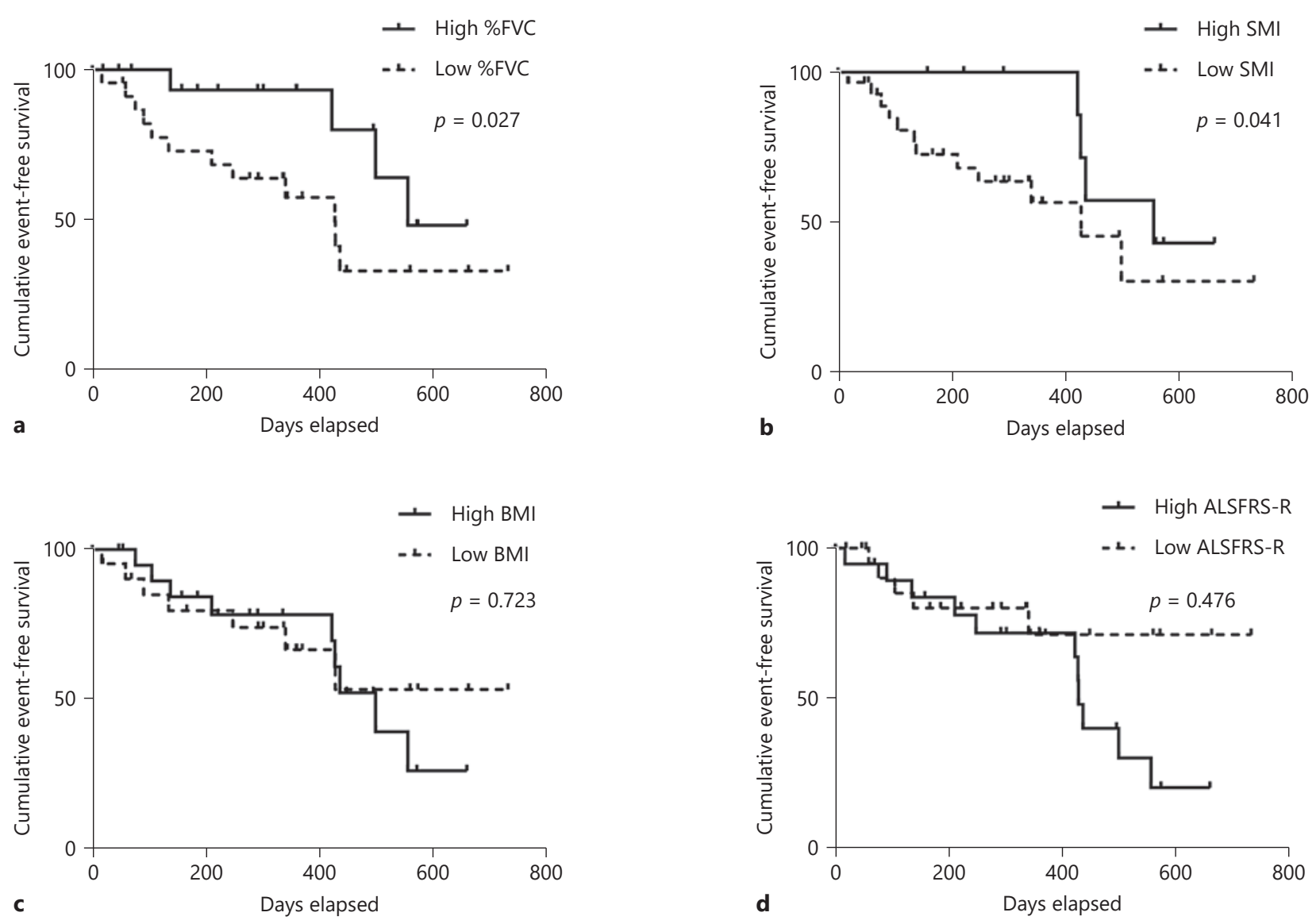

Fig. 3. Cumulative event-free survival. Kaplan-Meier curves depicting cumulative event-free survival, stratified by \%FVC (a), SMI (b), BMI (c), and (d) ALSFRS-R. Wilcoxon analysis was performed to analyze the data. \%FVC, percent forced vital capacity; SMI, skeletal muscle index; BMI, body mass index; ALSFRS-R, Revised Amyotrophic Lateral Sclerosis Functional Rating Scale; REE, resting energy expenditure.

significant factors affecting REE. Further, SMI and $\%$ FVC were significant factors associated with REE/ FFM as an indicator of metabolic change, showing that hypermetabolism occurred in patients with reduced muscle mass and \%FVC. Previous studies showed that the prognosis of ALS is associated with \%FVC [12-14], BMI [10], and ALSFRS-R score [11, 12]. However, in this study, we found a significant link to \%FVC alone, and not to BMI or ALSFRS-R score. This might be due to our relatively small sample size. Nevertheless, our results indicate that, together with early evaluation of BMI or ALSFRS-R, early evaluation of respiratory functions crucial for predicting prognosis. In addition, we identified SMI as a novel prognostic factor in the present study, suggesting that it can serve as a relatively sen- sitive index for predicting prognosis. The association between loss of muscle mass and prognosis has been reported in a variety of diseases $[40,41]$. Notably, sarcopenic obesity is also considered a poor prognostic factor [42-44]. This study demonstrated the importance of assessing muscle mass by measuring body composition in ALS, as sarcopenia may be overlooked when assessing body weight or BMI alone.

There are some limitations to this study. First, this was a retrospective single-center study, so the number of patients included was small. Hence, the significance of our results should be confirmed in a prospective multicenter study. Second, our cohort had a relatively lean body type, so the results might not be applicable to other populations. Median BMI was $20.3 \mathrm{~kg} / \mathrm{m}^{2}$ in our cohort, which 
is lower than that of ALS patients in Europe and North America $\left(23.7-27.1 \mathrm{~kg} / \mathrm{m}^{2}\right)$ [36, 45-51] and even low compared with that reported in other Asian populations $\left(21-22 \mathrm{~kg} / \mathrm{m}^{2}\right)[52,53]$.

Taken together, this study showed that metabolism is increased in ALS patients and that the Shimizu equation was a better predictive formula for TEE compared with $\mathrm{BEE} \times \mathrm{AF}$. Also, low SMI and low $\% \mathrm{FVC}$ were shown to be significantly associated with hypermetabolism. In addition to \%FVC, which has been reported as a prognostic factor, SMI may also be useful as a prognostic indicator.

\section{Statement of Ethics}

This study was approved by the Ethics Committee of Shiga University of Medical Science Hospital (approval No.: R2019003). The need for consent was waived, and an opt-out policy was applied instead.

\section{Conflict of Interest Statement}

The authors declare that they have no conflict of interest.

\section{Funding Sources}

This study was supported in part by a Grant-in-Aid for Scientific Research from the Ministry of Education, Culture, Sports, Science and Technology of Japan (18K11098 [MK]).

\section{Author Contributions}

M.K., S.B., and M.a.S. contributed to conceptualization and methodology. M.K., S.B., S.Y., A.I., N.N., R.N., N.O., A.K., I.Y., H.K., and M.i.S contributed to data acquisition. M.K., S.B., T.N., R.N., M.U., and M.a.S interpreted the data. M.K. and S.B. did the formal analysis. M.K. involved in writing - original draft. S.B., S.Y., A.I., T.N., N.N., R.N., N.O., A.K., I.Y., H.K., M.i.S, M.U., and M.a.S. involved in writing - review and editing. T.N., M.U., and M.a.S. supervised the study. All authors approved the final manuscript.

\section{References}

1 Desport JC, Preux PM, Truong TC, Vallat JM, Sautereau D, Couratier P. Nutritional status is a prognostic factor for survival in ALS patients. Neurology. 1999;53:1059-63.

2 Kasarskis EJ, Berryman S, Vanderleest JG, Schneider AR, McClain CJ. Nutritional status of patients with amyotrophic lateral sclerosis: relation to the proximity of death. Am J Clin Nutr. 1996;63:130-7.

3 Chio A, Mora G, Leone M, Mazzini L, Cocito D, Giordana MT, et al. Early symptom progression rate is related to ALS outcome: a prospective population-based study. Neurology. 2002;59:99-103.

4 Traynor BJ, Codd MB, Corr B, Forde C, Frost E, Hardiman OM. Clinical features of amyotrophic lateral sclerosis according to the El Escorial and Airlie House diagnostic criteria: a population-based study. Arch Neurol. 2000; 57:1171-6.

5 Chio A, Calvo A, Moglia C, Mazzini L, Mora G. Phenotypic heterogeneity of amyotrophic lateral sclerosis: a population based study. J Neurol Neurosurg Psychiatry. 2011;82:7406.

6 del Aguila MA, Longstreth WT Jr, McGuire V, Koepsell TD, van Belle G. Prognosis in amyotrophic lateral sclerosis: a populationbased study. Neurology. 2003;60:813-9.

7 Millul A, Beghi E, Logroscino G, Micheli A, Vitelli E, Zardi A. Survival of patients with amyotrophic lateral sclerosis in a populationbased registry. Neuroepidemiology. 2005;25: 114-9.
8 Marin B, Desport JC, Kajeu P, Jesus P, Nicolaud B, Nicol M, et al. Alteration of nutritional status at diagnosis is a prognostic factor for survival of amyotrophic lateral sclerosis patients. J Neurol Neurosurg Psychiatry. 2011; $82: 628-34$.

9 Jawaid A, Murthy SB, Wilson AM, Qureshi SU, Amro MJ, Wheaton M, et al. A decrease in body mass index is associated with faster progression of motor symptoms and shorter survival in ALS. Amyotroph Lateral Scler. 2010;11:542-8.

10 Dardiotis E, Siokas V, Sokratous M, Tsouris Z, Aloizou AM, Florou D, et al. Body mass index and survival from amyotrophic lateral sclerosis: a meta-analysis. Neurol Clin Pract. 2018;8:437-44.

11 Kimura F, Fujimura C, Ishida S, Nakajima H, Furutama D, Uehara H, et al. Progression rate of ALSFRS-R at time of diagnosis predicts survival time in ALS. Neurology. 2006;66: 265-7.

12 Kollewe K, Mauss U, Krampfl K, Petri S, Dengler R, Mohammadi B. ALSFRS-R score and its ratio: a useful predictor for ALS-progression. J Neurol Sci. 2008;275:69-73.

13 Czaplinski A, Yen AA, Appel SH. Forced vital capacity (FVC) as an indicator of survival and disease progression in an ALS clinic population. J Neurol Neurosurg Psychiatry. 2006;77: 390-2.

14 Schmidt EP, Drachman DB, Wiener CM, Clawson L, Kimball R, Lechtzin N. Pulmonary predictors of survival in amyotrophic lateral sclerosis: use in clinical trial design. Muscle Nerve. 2006;33:127-32.
15 Genton L, Viatte V, Janssens JP, Héritier AC, Pichard C. Nutritional state, energy intakes and energy expenditure of amyotrophic lateral sclerosis (ALS) patients. Clin Nutr. 2011; 30:553-9.

16 Muscaritoli M, Kushta I, Molfino A, Inghilleri M, Sabatelli M, Rossi Fanelli F. Nutritional and metabolic support in patients with amyotrophic lateral sclerosis. Nutrition. 2012;28: 959-66.

17 Desport JC, Torny F, Lacoste M, Preux PM, Couratier P. Hypermetabolism in ALS: correlations with clinical and paraclinical parameters. Neurodegener Dis. 2005;2:202-7.

18 Bouteloup C, Desport JC, Clavelou P, Guy N, Derumeaux-Burel H, Ferrier A, et al. Hypermetabolism in ALS patients: an early and persistent phenomenon. J Neurol. 2009;256: 1236-42.

19 Ngo ST, Steyn FJ, McCombe PA. Body mass index and dietary intervention: implications for prognosis of amyotrophic lateral sclerosis. J Neurol Sci. 2014;340:5-12.

20 Georges M, Morélot-Panzini C, Similowski T, Gonzalez-Bermejo J. Noninvasive ventilation reduces energy expenditure in amyotrophic lateral sclerosis. BMC Pulm Med. 2014;14:17.

21 Vaisman N, Lusaus M, Nefussy B, Niv E, Comaneshter D, Hallack R, et al. Do patients with amyotrophic lateral sclerosis (ALS) have increased energy needs? J Neurol Sci. 2009; 279:26-9. 
22 Ichihara N, Namba K, Ishikawa-Takata K, Sekine K, Takase M, Kamada Y, et al. Energy requirement assessed by doubly-labeled water method in patients with advanced amyotrophic lateral sclerosis managed by tracheotomy positive pressure ventilation. Amyotroph Lateral Scler. 2012;13:544-9.

23 Harris JA, Benedict FG. A biometric study of human basal metabolism. Proc Natl Acad Sci USA. 1918;4:370-3.

24 Shimizu T, Ishikawa-Takata K, Sakata A, Nagaoka U, Ichihara N, Ishida C, et al. The measurement and estimation of total energy expenditure in Japanese patients with ALS: a doubly labelled water method study. Amyotroph Lateral Scler Frontotemporal Degener. 2017;18:37-45.

25 Wang Z, Heshka S, Gallagher D, Boozer CN, Kotler DP, Heymsfield SB. Resting energy expenditure-fat-free mass relationship: new insights provided by body composition modeling. Am J Physiol Endocrinol Metab. 2000; 279:E539-45.

26 Nishikawa H, Shiraki M, Hiramatsu A, Moriya K, Hino K, Nishiguchi S. JSH guidelines for sarcopenia in liver disease (first edition): recommendation from the working group for creation of sarcopenia assessment criteria in the JSH. Hepatol Res. 2016;46(10):951.

27 Cedarbaum JM, Stambler N, Malta E, Fuller C, Hilt D, Thurmond B, et al. The ALSFRS-R: a revised ALS functional rating scale that incorporates assessments of respiratory function. BDNF ALS study group (Phase III). J Neurol Sci. 1999;169:13-21.

28 Weir JB. New methods for calculating metabolic rate with special reference to protein metabolism. J Physiol. 1949;109(1-2):1-9.

29 Sasaki M, Johtatsu T, Kurihara M, Iwakawa H, Tanaka T, Bamba S, et al. Energy expenditure in Japanese patients with severe or moderate ulcerative colitis. J Clin Biochem Nutr. 2010;47:32-6.

30 Takaoka A, Sasaki M, Kurihara M, Iwakawa $\mathrm{H}$, Inoue $\mathrm{M}$, Bamba $\mathrm{S}$, et al. Comparison of energy metabolism and nutritional status of hospitalized patients with Crohn's disease and those with ulcerative colitis. J Clin Biochem Nutr. 2015;56:208-14.

31 Shinsyu A, Bamba S, Kurihara M, Matsumoto $\mathrm{H}$, Sonoda $\mathrm{A}$, Inatomi $\mathrm{O}$, et al. Inflammatory cytokines, appetite-regulating hormones, and energy metabolism in patients with gastrointestinal cancer. Oncol Lett. 2020;20:1469-79.
32 Yasuhara S, Maekawa M, Bamba S, Kurihara M, Nakanishi N, Yamamoto T, et al. Energy metabolism and nutritional status in hospitalized patients with chronic heart failure. Ann Nutr Metab. 2020;76:129-39.

33 Long CL, Schaffel N, Geiger JW, Schiller WR, Blakemore WS. Metabolic response to injury and illness: estimation of energy and protein needs from indirect calorimetry and nitrogen balance. JPEN J Parenter Enteral Nutr. 1979; 3:452-6.

34 Wills AM, Hubbard J, Macklin EA, Glass J, Tandan R, Simpson EP, et al. Hypercaloric enteral nutrition in patients with amyotrophic lateral sclerosis: a randomised, double-blind, placebo-controlled phase 2 trial. Lancet. 2014;383:2065-72.

35 Ludolph AC, Dorst J, Dreyhaupt J, Weishaupt $\mathrm{JH}$, Kassubek J, Weiland U, et al. Effect of high-caloric nutrition on survival in amyotrophic lateral sclerosis. Ann Neurol. 2020;87: 206-16.

36 Kasarskis EJ, Mendiondo MS, Matthews DE, Mitsumoto H, Tandan R, Simmons Z, et al. Estimating daily energy expenditure in individuals with amyotrophic lateral sclerosis. Am J Clin Nutr. 2014;99:792-803.

37 Jesus P, Fayemendy P, Marin B, Nicol M, Sourisseau H, Boirie Y, et al. Increased resting energy expenditure compared with predictive theoretical equations in amyotrophic lateral sclerosis. Nutrition. 2020;77:110805.

38 Jesus P, Marin B, Fayemendy P, Nicol M, Lautrette $\mathrm{G}$, Sourisseau $\mathrm{H}$, et al. Resting energy expenditure equations in amyotrophic lateral sclerosis, creation of an ALS-specific equation. Clin Nutr. 2019;38:1657-65.

39 Miyake R, Tanaka S, Ohkawara K, IshikawaTakata K, Hikihara Y, Taguri E, et al. Validity of predictive equations for basal metabolic rate in Japanese adults. J Nutr Sci Vitaminol. 2011;57:224-32.

40 Bone AE, Hepgul N, Kon S, Maddocks M. Sarcopenia and frailty in chronic respiratory disease. Chron Respir Dis. 2017;14:85-99.

41 Ooi PH, Hager A, Mazurak VC, Dajani K, Bhargava R, Gilmour SM, et al. Sarcopenia in chronic liver disease: impact on outcomes. Liver Transpl. 2019;25:1422-38.

42 Kobayashi A, Kaido T, Hamaguchi Y, Okumura S, Shirai H, Yao S, et al. Impact of sarcopenic obesity on outcomes in patients undergoing hepatectomy for hepatocellular carcinoma. Ann Surg. 2019;269:924-31.
43 Nishigori T, Obama K, Sakai Y. Assessment of body composition and impact of sarcopenia and sarcopenic obesity in patients with gastric cancer. Transl Gastroenterol Hepatol. 2020;5: 22.

44 Stangl-Kremser J, Mari A, Lai LY, Lee CT, Vince R, Zaslavsky A, et al. Sarcopenic obesity and its prognostic impact on urologic cancers: a systematic review. J Urol. 2021: 101097JU0000000000001873.

45 Huisman MH, Seelen M, van Doormaal PT, de Jong SW, de Vries JH, van der Kooi AJ, et al. Effect of presymptomatic body mass index and consumption of fat and alcohol on amyotrophic lateral sclerosis. JAMA Neurol. 2015; 72:1155-62.

46 Hollinger SK, Okosun IS, Mitchell CS. Antecedent disease and amyotrophic lateral sclerosis: what is protecting whom? Front Neurol. 2016;7:47.

47 Delaye JB, Patin F, Piver E, Bruno C, Vasse M, Vourc'h P, et al. Low IDL-B and high LDL-1 subfraction levels in serum of ALS patients. J Neurol Sci. 2017;380:124-7.

48 Dedic SI, Stevic Z, Dedic V, Stojanovic VR, Milicev M, Lavrnic D. Is hyperlipidemia correlated with longer survival in patients with amyotrophic lateral sclerosis? Neurol Res. 2012;34:576-80.

49 Sutedja NA, van der Schouw YT, Fischer K, Sizoo EM, Huisman MH, Veldink JH, et al. Beneficial vascular risk profile is associated with amyotrophic lateral sclerosis. J Neurol Neurosurg Psychiatry. 2011;82:638-42.

50 Dorst J, Kühnlein P, Hendrich C, Kassubek J, Sperfeld AD, Ludolph AC. Patients with elevated triglyceride and cholesterol serum levels have a prolonged survival in amyotrophic lateral sclerosis. J Neurol. 2011;258:613-7.

51 Chio A, Calvo A, Bovio G, Canosa A, Bertuzzo D, Galmozzi F, et al. Amyotrophic lateral sclerosis outcome measures and the role of albumin and creatinine: a population-based study. JAMA Neurol. 2014;71:1134-42.

52 Huang R, Guo X, Chen X, Zheng Z, Wei Q, $\mathrm{Cao} B$, et al. The serum lipid profiles of amyotrophic lateral sclerosis patients: a study from south-west China and a meta-analysis. Amyotroph Lateral Scler Frontotemporal Degener. 2015;16:359-65.

53 Wei QQ, Chen Y, Cao B, Ou RW, Zhang L, Hou Y, et al. Blood hemoglobin A1c levels and amyotrophic lateral sclerosis survival. $\mathrm{Mol}$ Neurodegener. 2017;12:69. 